\author{
Military Technical College \\ Kobry Elkobbah, Cairo, \\ Egypt.
}

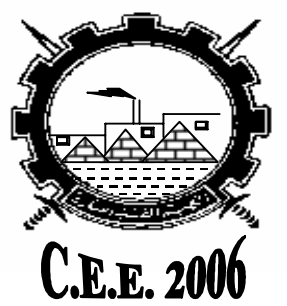

$3^{\text {rd }}$ International Conference

On

Chemical \& Environmental Engineering

\title{
EFFECT OF DIFFERENT BINDERS ON THE PERFORMANCE OF SOME ADVANCED PLASTIC BONDED EXPLOSIVES
}

\author{
Radwan M. A. * , Seleet M. M. **and Zaki M. G. **
}

\section{ABSTRACT}

Plastic bonded explosives (PBXs) form a new family of the modern types of explosives based on elastomeric binders,. The high mechanical strength, in addition to the good explosive characteristics, long term thermal stability and relative safe ty to handling and usage have stimulated the research and development work in this field. This investigation is directed to the formulation of RDX based PBX compositions different binder such as polyurethane based on HTPB, and GAP, and fluorocarbons (fluorel) as energetic polymeric binders. Slurry and casting techniques were used to prepone of different explosive compositions based on fluorel binder $(5,8,11,15$ and $20 \%$ fluorel) and polyurethane binders based on HTPB or GAP (12, 15,18 and $21 \%$ ) contents. The study measures the explosive characteristics.

Moreover, the effect of addition aluminum powder on the sensitivity and performance of PBX these formulations was investigated.

It was found into the investigated PBX compositions have high performance and reasonable sensitivity to different impulses. It is proved that these PBX formulations could be prepared by simple techniques.

\footnotetext{
* British University in Egypt (BUE).

${ }^{* *}$ Egyptian Armed Forces.
} 


\section{INTRODUCTION}

Many recent researches were focused on the preparation, characterization and applications of modern energetic polymeric binders with different types of energetic materials, specially sensitive high explosives to achieve better mechanical and explosive properties and also lower vulnerability (1-17).

In general PBXs mainly consist of a polymeric binder, an explosive filler and other minor ingredients such as catalysts, plasticizers, curing and bonding agents. These additives are used to improve processing and physical properties.

Hydroxyl terminated polybutadiene (HTPB), glycidyl azide polymer (GAP) and hexafluoropropylene- vinyledene fluoride ( 0.8/0.2) copolymer (Fluorel) as energetic polymeric binders of different families were employed in this work to develop PBXs with significantly lower vulnerability to battlefield environment than current explosives without sacrificing performance or increasing cost.

Cyclotrimethylene-trinitramine (RDX) was selected to be the explosive filler since it is considered as one of the most brisant high explosives.

\section{EXPERIMENTAL}

\section{Materials}

All the chemicals used in this work; HTPB, GAP, Fluorel, Hexamethylene diisocyanate (HMDI), Dioctylazelate plasticizer (DOZ), RDX and Methyl ethyl ketone (MEK) were of high purity.

\section{Preparation of PBX Compositions Based on RDX and Fluorel}

The preparation was carried out using the slurry technique (18-19). Fluorel was completely dissolved in MEK and RDX was slowly added to the laquer. After 20-30 minutes about $400 \mathrm{ml}$, more than the volume of MEK, of distilled water was poured drop-wise and stirring was continued for 30 minutes. Temperature was increased to evaporate MEK and the formed beads were filtered off, washed with water and dried at $70^{\circ} \mathrm{C}$.

The compositions and summary formula of the prepared formulations are listed in Table (1). 


\section{Preparation of PBX Compositions Based on RDX and HTPB or GAP}

These compositions were prepared by employing the cast technique. The prepolymers used in this work were HTPB and GAP (HTPB of 0.83 and GAP of 2.44 measured $\mathrm{mg}$ equivalent $\mathrm{OH} / \mathrm{g}$ HTPB and GAP respectively) the plasticizer (DOZ), was used with HTPB only. The prepolymer and the plasticizer were mixed together at $50-60^{\circ} \mathrm{C}$ then RDX was added and thoroughly mixing was continued. At the end the curing agent (HMDI) of $11.9 \mathrm{mg}$ equivalent NCO/g HMDI was added and mixing was carried out for relatively short time. The mixture is then poured in suitable moulds and polyvinyl chloride (PVC) tubes to measure the explosive characteristics and detonation velocity respectively after curing which was carried out at $55^{\circ} \mathrm{C}$ for two weeks.

The compositions and summary formula of these prepared formulations are listed in Table (1).

\section{Sensitivity of Prepared Formulations}

Sensitivity to impact was determined by employing Julius Peters KG (Germany made) apparatus, using $2 \mathrm{Kg}$ falling weight according to the standard technique. Sensitivity to friction was determined using Julius Peters KG apparatus. The frictions test was conducted in such a way that the loading on the pistil was increased and the percentage of initiation was determined. The load at which $100 \%$ initiation was determined and thus the force in Newton could be estimated. The sensitivity to heat was obtained by measuring the ignition temperature for the prepared PBX samples and also by determining the temperatures corresponding to certain constant delay periods ( 2 seconds) of ignition) using Julius Peters apparatus. To determine the ignition temperature, the temperature was uniformly increased $\left[5^{\circ} \mathrm{C} / \mathrm{min}\right]$ until the explosion conversion occurred. Detonator number 8 was employed to determine the cap sensitivity of the prepared formulations according to standard technique.

\section{The Assessment of Brisance}

Assessment of brisance of the prepared samples (i.e the destructive effect of a charge on its immediate vicinity) was done using Kast technique (20), employing PHYWE testing kit, where 2 grams of the explosive charge was pressed to a density of $1.6 \mathrm{~g} / \mathrm{cm}^{3}$ into an aluminium tube of $30 \mathrm{~mm}$ height, $12 \mathrm{~mm}$ inside diameter and 4 $\mathrm{mm}$ wall thickness. Special test detonator with $0.2 \mathrm{~g}$ of lead azide and $0.4 \mathrm{~g}$ of RDX was prepared on site to initiate the explosive charge. The copper crushers used are of $10.5 \mathrm{~mm}$ height and $7 \mathrm{~mm}$ diameter. The deformation (final lengths) of copper crushers was determined after the explosion of the charges and converted into force units according to the calibration table of the copper crusher static compression force test supplied by PHYWE system GMBH, Germany. 


\section{Detonation Velocity of the Prepared PBX Formulations}

The prepared PBX formulations were pressed to a density $1.6 \mathrm{~g} / \mathrm{cm}^{3}$ in PVC tubes of $22 \mathrm{~mm}$ inside diameter and about $2 \mathrm{~mm}$ thickness. The Exploment -Fo- Multi Channel, Supplied by Kontiniro AG. (Swiss made) was used to measure the detonation velocity of these formulations. The time interval for a detonation wave to travel a known distance between the two fiber optic probes in microseconds was displayed with the calculated detonation velocity in $\mathrm{m} / \mathrm{s}$.

\section{RESULTS AND DISCUSSION}

\section{Summary Formula and Oxygen Balance of PBX Formulations}

The summary formula for $1 \mathrm{~kg}$, oxygen balance and internal energy of formation of the prepared PBX formulations based on different binders (HTPB, GAP or fluorel) were calculated and listed in table (1). It is clear that oxygen balance of the prepared samples based on HTPB is strongly negative $(-56:-82)$ while that of pure RDX is slightly negative $(-21)$ and this is due to the very low content of oxygen in polyurethane binder based on HTPB. The oxygen balance of formulations based on GAP is higher (-33: -42) when compared with those based on HTPB due to the higher content of oxygen in GAP structure. The samples based on fluorel has slightly negative oxygen balance (-241.32), and this of course due to the high content of fluorine atoms in this binder.

Oxygen balanace strongly affects the equilibrium gaseous products composition. Samples based on HTPB having strongly negative oxygen balance, forms of carbon soot. Hence, the decrease in the no. of moles of gaseous products would result in a decrease of all dependent explosive characteristics such as specific volume, force, brisance, and detonation velocity. PBX formulations based on GAP have relatively lower oxygen balance negativity and hence, less possibility of carbon soot formation and accordingly improved explosive characteristics may be expected.

Moreover, the formulations based on fluorel have the least negativity of oxygen balance, hence no formation of carbon soot is expected. Also, hydrogen fluoride gas formation should enhance the explosive characteristics.

The values of oxygen balance for aluminized compositions based on HTPB or GAP were found to be more negative than their counterparts due to the existence of aluminum which is classified as a fuel.

\section{Sensitivity of PBX Formulations to Different Initial Impulses}

For all the prepared PBX formulations based on RDX and (HTPB, GAP or fluorel), the values of upper limit of sensitivity to impact (minimum height of falling hammer at which $100 \%$ explosions occur out of 6 repeated successive trials) were determined. 
The corresponding values in joules are listed in table (2) with some literature values for comparison.

From table (2), it is clear that the sensitivity of RDX to impact is generally decreased by increasing the binder content regardless of the binder type.

However; PBX formulations based on polyurethane binder (HTPB or GAP) 


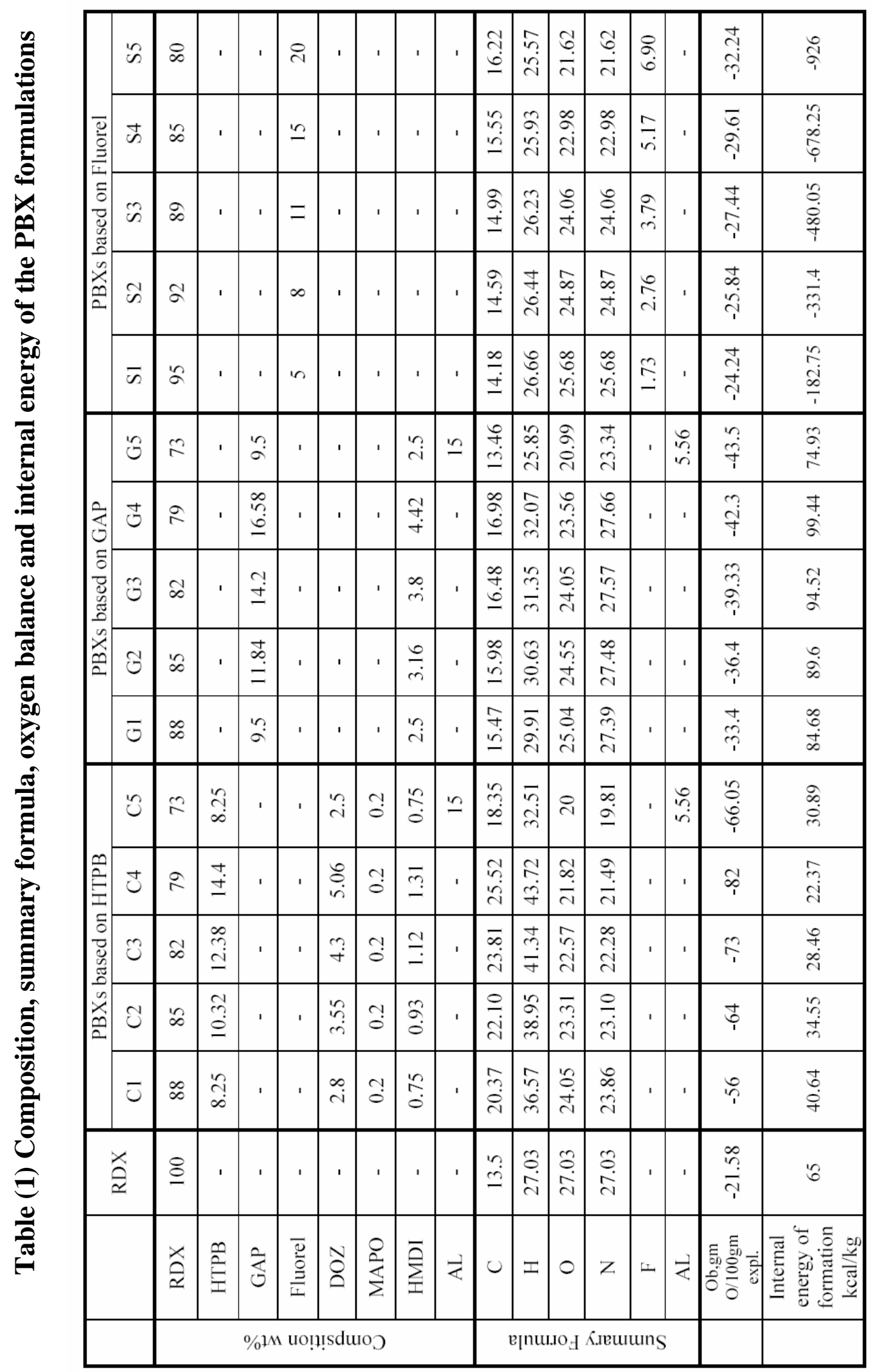


have lower sensitivity to impact than those formulations based on fluorel. These results reveal the higher degree of safety of these formulations towards impact impulses, a criterion required for bombs, and rocket warheads.

The increasing of GAP content in the PBX formulations based on GAP has exceptionally high and marked effect on decreasing the sensitivity of these formulations to impact. The formulation containing $15 \%$ polyurethane based on GAP decreased the sensitivity to impact by $100 \%$ while the formulation containing $21 \%$ of same binder lowered the sensitivity to impact by $211 \%$, which is considered as the lowest sensitivity to impact among all other prepared formulations (compared with that of pure RDX). With respect to PBX formulations based on RDX and HTPB binder, a similar situation to that of GAP formulations was obtained.

The values of upper limit of sensitivity to impact which were found in litretaure and listed in table (2) for similar formulations are about the same as that experimentally determined in this work.

Table (2) Values of upper limit of sensitivity to impact of the PBX formulations

\begin{tabular}{|c|c|c|}
\hline $\begin{array}{l}\text { Literature values } \\
(\mathrm{J})\end{array}$ & $\begin{array}{c}\text { Expérimental values } \\
(\mathrm{J})\end{array}$ & Composition \\
\hline $7.4[21]$ & 7.1 & Pure RDX \\
\hline $8.82[22]$ & 8.82 & S1 ( $5 \%$ fluorel) \\
\hline- & 9.11 & S2 (8\% fluorel) \\
\hline- & 9.70 & S3 (11\% fluorel) \\
\hline $10.58[22]$ & 10.78 & S4 (15\% fluorel) \\
\hline $11.34[22]$ & 11.78 & S5 (20\% fluorel) \\
\hline $11.3[23]$ & 11.27 & G1 (12\% PU/GAP) \\
\hline $14.21[23,24]$ & 14.21 & G2 (15\% PU/GAP) \\
\hline- & 8.62 & G3 (18\% PU/GAP) \\
\hline $20[24]$ & 22.05 & G4 (21\% PU/GAP) \\
\hline- & 35.77 & G5 (12\%PU/GAP+15\%Al) \\
\hline - & 14.21 & C1 (12\%PU/ HTPB) \\
\hline- & 15.68 & C2 (15\% PU/HTPB) \\
\hline- & 16.66 & C3 (18\%PU/ HTPB) \\
\hline- & 18.13 & C4 (21\% PU/HTPB) \\
\hline- & 21.56 & C5 ((12\% PU/HTPB+15\%Al) \\
\hline
\end{tabular}

For aluminized compositions based on $12 \%$ GAP and $15 \%$ Al the value of sensitivity to impact were decreased by more than $300 \%$ when compared with the similar compositions containing $12 \%$ GAP and Al-free. Similar situation for aluminized composition based on $12 \%$ HTPB and $15 \%$ Al, the value of sensitivity to impact was decreased by about $50 \%$ when compared with the similar composition containing $12 \%$ HTPB and Al-free.

This great effect of aluminum, on decreasing the sensitivity to impact, is attributed to the fact that aluminum is considered as an inert ingredient in these formulations. 
The upper limit of the sensitivity to friction (minimum force which gives 100\% explosions out of six successive trials) of pure RDX was also determined and found to be $120 \mathrm{~N}$, in good agreement with the reported values. However; for all other prepared formulations based on RDX and fluorel, GAP or HTPB, no indication of initiation was noticed even when applying the maximum force $(360 \mathrm{~N})$ of the test apparatus.

These results can be attributed to the satisfactory coating effect of the different used binders to the RDX crystals by a thin layer minimizing the friction between these crystals.

The values of the measured ignition temperature for all the prepared formulations are illustrated in figure (1). It is clear that for PBXs based on RDX and fluorel, the values of ignition temperature seem to be constant and very close to that of pure RDX, while for other compositions based on GAP or HTPB the values obtained for ignition temperature were slightly lower than that of pure RDX. This can be attributed to the fact that the coating of polyurethane based on GAP or HTPB acts as heat sensitizing medium because its softening temperature is less than $152^{\circ} \mathrm{C}$. On the other hand, fluorel, which has a softening temperature of $290^{\circ} \mathrm{C}$, does not behave similar to polyurethane based on HTPB or GAP.

The values of ignition temperature corresponding to constant delay periods (2 seconds), for the prepared PBX compositions and pure RDX, are listed in table (3). The effect of increasing binder content, in PBX formulations based on GAP, was not significant, but in case of PBX formulations based on HTPB or fluorel, the effect was clear.

For all the tested PBX formulations, it was found that all compositions were sensitive to the detonation wave obtained from detonator number 8 .

It is clear that although the coating of RDX grains by the employed binders (GAP, HTPB or fluorel) markedly decreases the sensitivity to impact and friction, yet this coating does not affect the sensitivity of RDX crystals to detonation wave. This result emphasizes the choiceof detonator no.8 for initiation of all the prepared formulations in different applications. 
Table (3) Values of ignition temperature corresponding to 2 seconds delay period for the prepared PBX formulations

\begin{tabular}{|c|c|}
\hline Compositions & Experimental values (C) \\
\hline Pure RDX & $\mathbf{2 9 5}$ \\
S1 (5\% fluorel) & 300 \\
S2 (8\% fluorel) & 305 \\
S3 (11\% fluorel) & 325 \\
S4 (15\% fluorel) & 345 \\
S5 (20\% fluorel) & 382 \\
\hline G1 (12\% PU/GAP) & 296 \\
G2 (15\% PU/GAP) & 300 \\
G3 (18\% PU/GAP) & 303 \\
G4 (21\% PU/GAP) & 305 \\
G5 (12\%PU/GAP+15\%Al) & 300 \\
\hline C1 (12\% PU/HTPB) & 300 \\
C2 (15\% PU/HTPB) & 305 \\
C3 (18\% PU/HTPB) & 310 \\
C4 (21\% PU/HTPB) & 322 \\
C5 (12\% PU/HTPB+15\%Al) & 325 \\
\hline
\end{tabular}

\section{Performance of the Prepared PBX Formulations}

\section{Detonation Velocity of the Prepared PBX Formulations}

For all the prepared PBX formulations based on RDX and different binder types (fluorel, and polyurethane based on GAP or HTPB), the detonation velocity was determined and illustrated in figure (2).

The detonation velocity of explosives is one of the important terms which represent the rate of energy delivery through explosive conversion. From the obtained results we can find that the type and content of binder have significant effect on detonation velocity of the prepared PBX formulations.

It is clear that formulations containing 5,8 , or $11 \%$ fluorel have higher detonation velocity than those based on polyurethane (HTPB or GAP). This may be attributed to the higher content of energetic fluorine atoms $(65.5 \%$ by weight) in fluorel binder structure.

It is obvious that detonation velocity generally decreases by increasing the binder content. However, the trend of decrease is different in each case. 


\section{Brisance of the Prepared PBX Formulations}

The brisance of an explosive depends mainly on explosive density, detonation velocity (rate of energy delivery), gaseous products composition, and explosion temperature. The values of brisance were determined for pure RDX and all the prepared PBX formulations. The dependence of the brisance on binder content for the employed binders is illustrated in figure (3).

The value of brisance of pure RDX was found to be $1188 \mathrm{kp}$ which is in excellent agreement with values found in literature. For formulations based on HTPB, the values of brisance were slightly linearly decreased, this decrease is related to the decrease of the brisant high explosive content (RDX) and hence the decrease of oxygen balance (more negative), number of moles of gaseous products and detonation velocity of the prepared PBX formulations. The values of brisance for formulations based on GAP are higher than those of corresponding compositions based on HTPB. GAP is more energetic binder than HTPB due to better oxygen balance and higher calorific value.

The compositions based on fluorel have the same behavior i.e the brisance decreases with increasing the binder content. The relatively higher values of brisance for formulations based on fluorel than other compositions, may be explained by the fact that fluorel is considered as one of the most energetic binders containing high percent of fluorine atoms, $(65.5 \%$ weight percent of the binder) which enhances all the energetic and explosive characteristics.

\section{REFERENCES}

[1] P.Sjoberg, H.Hytti, R.Strandberg, A.Kariniemi and M.Muilu;"PBX with Insensitive RDX, a New EIDS. Substance For Under Water Use", $33^{\text {rd }}$ International Annual Conference of ICT, Karlsruhe, Germany, 2002.

[2] A.Provates;"Energetic Polymers and Plasticizers for Explosive Formulations", a Review for Recent Advances, Weapons Systems Division Aeronautical and Maritime Research Lab., 2000.

[3] P.Gerber, C.Hubner and K.Menke;"Characterization of the Matrix Filler Properties of the GAP/RDX Propellant System",31st International Annual Conference of ICT, Karlsruhe, Germany, 2000.

[4] V.Weiser, N. Eisenreich, W. Eckl, S. Eisele and K.Menke;"Burning Behavior of CL-20/GAP and HMX/GAP Propellants", 31st International Annual Conference of ICT, Karlsruhe, Germany, 2000.

[5] G. Manser, R. Fletcher and M. knight;"High Energy Binders", ONR Final Report Contract No. N00014-82-c-0800, Aerojet Solid Propulsion Company, 1985.

[6] G.Manger and D. Ross;"Synthesis of Energetic Polymers", ONR Final Report, Contract No. 0014-79-c-0525, Aerojet Solid Propulsion Company, Sacramento, 1982.

[7] R.W. Millar, N.C Paul and D. Richard;" Process for Producing High Energy Materials", GB Patent No. 2181124A, 1987. 
[8] P.Bunyan, B. Cunnliffe, A. Torry and H. Bult;"Stability Studies on End Modifications Poly GLYN", Insensitive Munitions and Energetic Materials Technology Symposium, Orlando,1997.

[9] J.Akhavan and T.Burke;"Polymer Binder for High Performance Explosives", Propellants, Explosives and Pyrotechnics 17, 271-274,1992.

[10] Manser;"Difluoramino Oxetanes and Polymers Formed for Use in Energetic Formulations", US patent no.5272-249,1993.

[11] C. Leach, P. Flower, R. Hollands, S. Flynn, E. Marshall and J. Kendrick;"Plasticizers in Energetic Formulations, UK Overview", $29^{\text {th }}$ International Annual Conference of ICT, Karlsruhe, Germany,1998.

[12] D. Kasprzyk, D. Bell, R. Flesner and S. Larson;"Characterization of a Slurry Process Used to Make a PBX", Propellants, Explosives and Pyrotechnics 24, 333-338, 1999.

[13] R. Kent;"Cast PBX B2238 for Small-Caliber High Performance Insensitive Munitions", Propellants, Explosives and Pyrotechnics 22, 65-70, 1997.

[14] M. Radwan; "Explosive Characteristics of Aluminized PBXs Based on HMX and Polyurethane Binder", 32nd International Annual Conference of ICT, Karlsruhe,Germany,2001.

[15] S. Chen, Y. Shun and S. Mengshen;"A Comparative Study of Thermal and Insensitive Characteristics of GAP/HMX and HTPB/HMX Systems", 24th International Annual Conference of ICT, Karlsruhe,Germany,1993.

[16] M.Radwan;"Sensitivity and Brisance of PBXs Based on HMX and Fluorel",32nd International Annual Conference of ICT, Karlsruhe, Germany,2001.

[17] M. Ismail, M. Radwan and W. El-meligy;"Preparation and Characterization of PBXs Based on NP and Fluorel Binder", 1st International Conference on Chemical \& Environmental Engineering , MTC, Cairo, Egypt,2002

[18] S. Kaye, "Encyclopedia of Explosives and Related Items", Part 2700, Volume 8, 1978.

[19] D.J. Kasprzyk, D.A. Bell, R.L. Flesner and S.A. Larson, 'Characterization of a Slurry Process Used to Make a Plastic Bonded Explosive", Propellants, Explosives, and Pyrotechnics 24, 333-338, 1999.

[20] M. Suceska, "Test Methods for Explosives", Springer-Verlage, 1995.

[21] J. Kohler and R. Meyer; "Explosives", $4^{\text {th }}$ revised and extended edition, Germany, 1993

[22] A. Ekhlas; Preparation and Characterization of Explosive Sheets Used in Reactive Armours", M.Sc. Thesis, MTC, Cairo, Egypt, 2002.

[23] H. Adnan; "Preparation and Characterization of Some Energetic Materials Used In Rocket Propellants and High Explosives", Ph.D. Thesis, MTC, Cairo, Egypt, 2002.

[24] P. Brousseau, S. Thiboutot and E. Diaz, "New Melt-Cast Explosives Based on Energetic Thermoplastic Elastomers", $32^{\text {nd }}$ International Annual Conference of ICT, Karlsruhe, Germany, 2001. 
Proceeding of the $3^{\text {rd }}$ CEE Conference 16-18 May 2006

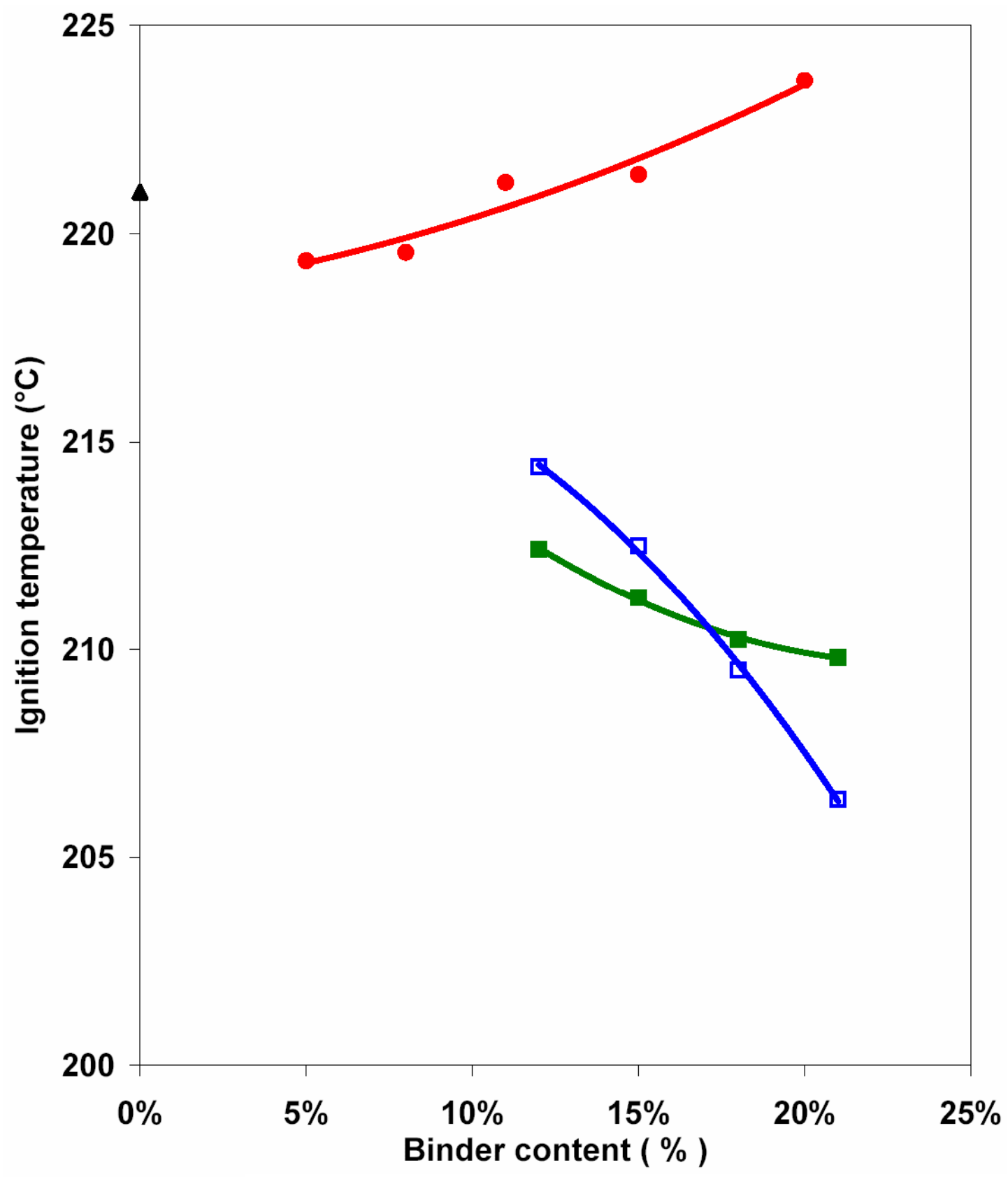

- FLOUREL

- GAP

HTPB

- RDX

Fig. (1) Dependence of ignition temperature values of prepared PBX formulations on binder content 
Proceeding of the $3^{\text {rd }}$ CEE Conference 16-18 May 2006

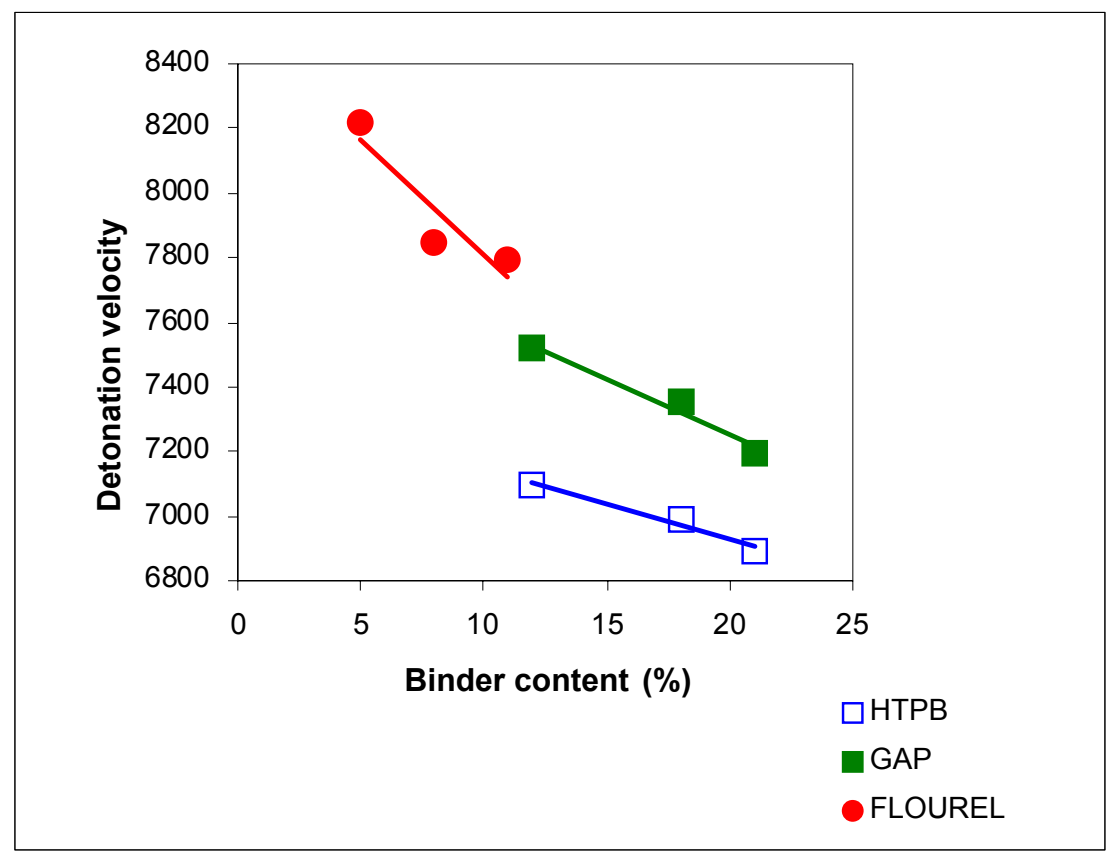

Fig. (2) Variation of detonation velocity with binder content for the prepared PBX formulations 
Proceeding of the $3^{\text {rd }}$ CEE Conference 16-18 May 2006

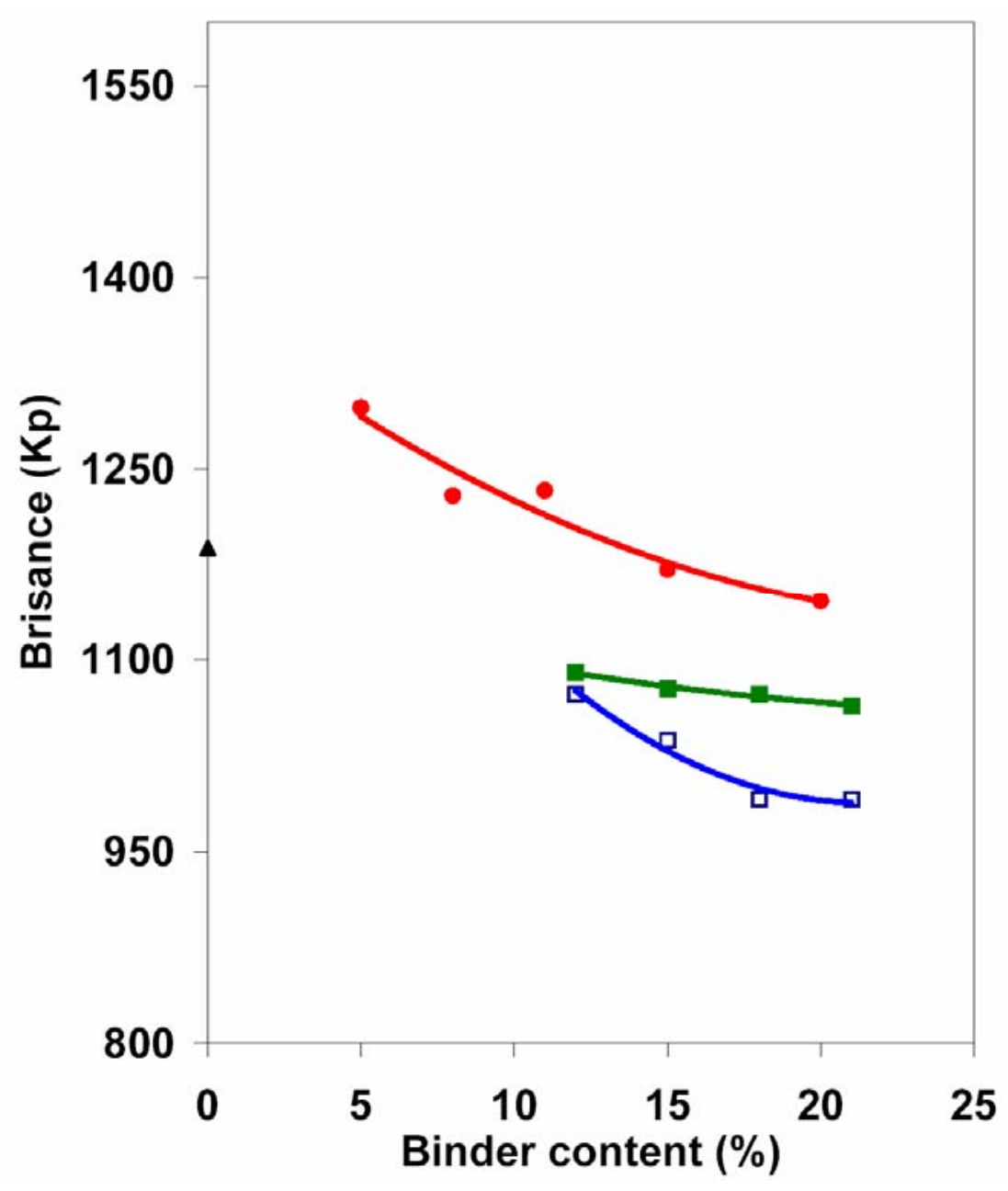

Fig. (3) Effect of binder content on the values of brisance for the prepared PBX formulations 